\title{
Use of a medication passport in a disabled child seen across many care settings
}

\author{
Barry Jubraj, ${ }_{1}^{1}$ Mitchel Blair ${ }^{2}$
}

${ }^{1}$ Department of Pharmacy, Chelsea \& Westminster Hospital NHS Foundation Trust, London, UK

${ }^{2}$ Department of Medicine, Imperial College, Middlesex, UK

\section{Correspondence to}

Professor Barry Jubraj, barry.jubraj@chelwest.nhs.uk

Accepted 29 January 2015

\section{SUMMARY}

Written information for patients about their medicines has demonstrable benefits for their understanding and adherence. In the UK, no single, complete record of medications for individual patients can be guaranteed. Therefore, patients and carers are often relied on to recall the complete medication list, which can be a challenge given multiple and potentially stressful appointments. Wide-ranging feedback suggests that a medication 'passport' developed by the National Institute for Health Research Collaboration for Leadership in Applied Health Research and Care North West London (NIHR CLAHRC NWL) has benefited elderly patients, who often attend many appointments where the current medication list may not be available. We describe the use of this passport (known as 'My Medication Passport'-MMP) in a child with multiple disabilities. The practical advantages are explored, including the potential for a paediatric version to facilitate discussions around the administration of medicines. MMP is an early example of a useful tool to help children and young people, parents and carers to manage medicines more effectively.

\section{CASE PRESENTATION}

The patient is a happy, secure and contented 8 -year-old boy with Down's syndrome. He attends a special school and his comorbidities include asthma, hypothyroidism, recurrent ear infections and moderate-to-severe hypotonia. He has severe gastro-oesophageal reflux disease with swallowing and feeding difficulties, as diagnosed by videofluoroscopy. This requires all his liquids to be thickened. The patient wears spectacles, hearing aids, is a wheelchair user and has a severe learning difficulty. He is supported regularly by general practice, the school nurse, ear nose and throat (ENT) specialists, general and community paediatrics, dietetics, specialist dentistry and ophthalmology. Medicines are a key part of his treatment, along with physiotherapy, speech and occupational therapy.

The patient is cared for by his parents (a pharmacist and a nurse) who, like many others, report feeling overwhelmed by multiple appointments, and find repeatedly explaining his social and medical history (including the medicines list) to be draining. Many clinicians rely on his parents for up-to-date information about the different professional interventions, including an up-to-date medication list. An example where the lack of an up-to-date medication list led to a potential medication-related problem was the prescription of azithromycin for an ear infection by an ENT surgeon. There is a documented drug interaction between azithromycin and domperidone, a medicine used regularly to treat the patient's gastrooesophageal reflux.

The patient's parents report that they have received no proactive support or advice from professionals about administration of his medicines. For example, he takes montelukast, omeprazole and domperidone each evening. $\mathrm{He}$ is likely to require levothyroxine in future. The parents have developed their own method to administer these medicines by dissolving montelukast and omeprazole tablets in a small volume of water in an egg-cup, adding domperidone liquid, and thickening with Resource Thicken-Up. The mixture is spooned down immediately.

\section{GLOBAL HEALTH PROBLEM LIST}

- A lack of a single, complete medication list for patients in the UK;

- The associated risks of interacting medicines being prescribed by clinicians oblivious to other medicines being taken by the patient;

- The draining and stressful experience of recalling and explaining the history and medication list, reported by many patients and carers, including this patient's parents;

- The lack of routine dialogue between professionals and parents/carers about the administration of medicines to disabled children and young people.

\section{GLOBAL HEALTH PROBLEM ANALYSIS}

My Medication Passport (MMP) is an awardwinning, patient-designed and patient-held record of medicines. It is available as a pocket-sized booklet and as a smartphone app, which has been widely publicised as an aid to medicines management, particularly for elderly patients on multiple medicines. ${ }^{1}$ Since the launch of MMP in April 2013, nearly 50000 pocket booklets have been ordered by pharmacies, hospitals, charities, general practitioner practices, nursing homes and patients, across England and Scotland; and over 3000 downloads of the app have been made in 37 countries worldwide. $^{2}$

MMP was developed by the North West London Collaboration for Leadership in Applied Health Research and Care (NWL CLAHRC)-funded 'Improving prescribing for the elderly' group, in collaboration with the National Institute for Health Research (NIHR) Imperial Patient Safety Translational Research Centre. Patients and carers were central to the development, rollout and 
evaluation of MMP. The MMP project aimed to improve communication about medicines across care settings and to reduce inappropriate prescribing for older patients. MMP can help promote a shift away from a traditional unidirectional flow of information towards the patient, instead promoting the development of a culture where patients are partners in their care. This notion has been endorsed particularly by the mental health charities MIND and MENCAP, who support the use of MMP. Interest has also recently been shown by the Metropolitan Police, Down's Syndrome Association and homeless charities.

This patient's father (BJ-coauthor of this case), joined the CLAHRC pharmacy team in 2014 and felt that MMP would be helpful for his son. He volunteered to pilot MMP in the spring of 2014. It did not take long for the patient's mother to enter medication details into the MMP, which contains pages entitled 'current medicines' on which are blank tables that are completed by hand. Changes can be made by hand in the pages entitled 'changes to my medicines'. The completed MMP provided, for the first time, a single medication record that belonged to the family and gave a simple overview of all medication (including changes) for clinicians in any setting to see 'at-a-glance'. The patient's parents have found it convenient to carry and update; and subsequently, in three key appointments in the community and hospital settings (including a surgical episode), the MMP has taken considerable pressure off explaining the patient's medicines, reducing the risk of error in recalling the relevant detail. We appreciate that this patient's parents are health professionals, which could theoretically provide an advantage in using MMP. We are confident, however, that lay parents and carers would be able to use MMP easily, because the layout was designed by patients and we envisage that the use of a future paediatric version would be facilitated by a paediatric pharmacist.

To our knowledge, this is the first published case of MMP use in a child, and illustrates afresh that children with complex needs are seen across care settings, and receive multiple prescriptions that may not be known to the whole clinical team providing care. Many disabled children and young people with special needs require regular and multiple medicines, and the potential for medicines-related risks such as adverse effects and drug interactions is high. In some cases, there may be alternative methods of medicines administration, particularly through feeding tubes, with an increased risk of drug-drug and drug-food interactions. Other risks include the problem that some specially prepared liquid medicine formulations may have a short shelf life. ${ }^{3}$ MMP offers the opportunity to monitor potential medicines-related problems and to promote a dialogue between parents/carers and their clinicians. Since MMP belongs to the parents, carers and young person, there can be a real sense of ownership and empowerment, which the patient's parents reported experiencing.

Paediatric users of MMP may benefit in the same way as some older patients who were reported as not being interested in their own care, but were 'activated' by the MMP. Some older children may, with help, be able to complete their MMP, write in it or even draw in it. MMP can change such individuals' perspectives and provide a tangible resource to initiate conversations with their HCPs that may hitherto not have been considered. ${ }^{2}$ Diabetes and asthma are two long-term conditions where such a passport might help encourage young patients in supporting self-care. ${ }^{4}$

We believe that MMP can make an important contribution to the management of medicines for children, young people, and their parents and carers. MMP may be one method to offer parents and carers an opportunity to be more empowered in discussing medication-related issues with clinicians across care settings. It puts parents and carers in control of the medication

\section{Patient's perspective}

As the patient's mother I have found MMP to be very helpful, particularly in not having to explain every detail about medicines at his many clinic appointments. I have made some suggestions to adapt MMP for use in other children with chronic conditions, particularly around recording exactly how we give medicines and being able to document if a child has special needs. I feel sure that MMP has real potential for use in children on multiple medications like my son. I hope that the paediatric community will consider an adapted MMP as a tool that can help many children like mine, and their families/carers, to manage medicines better in partnership with their clinicians. I am certain that many parents and carers of children with complex medical needs face the same challenges but without our medical background-they really need the help that an adapted MMP could provide.

record, allows an overview of the complete medication list for clinicians to see before prescribing, and promotes discussion about medicines administration, particularly if reviewed by a paediatric pharmacist. A particular advantage may be when a child is admitted acutely and parents/carers may not be present all the time. There is a case for keeping their MMP with the medication record during the admission.

Parents sometimes have to be inventive about getting medicines into children, unbeknown to their clinicians, and like this patient's parents, may never have received proactive advice on medicines administration before. Inappropriate administration can lead to inactivation of medicines and it is important for a healthcare professional to be involved.

We believe that MMP may require modifications in structure and method for effective use in children and young people. Our recommendations for a paediatric version are as follows:

\section{Learning points}

- Many patients with a complex history are prescribed a range of medicines that may not be known to all clinicians who care for them. It can be draining for patients and carers to explain or recall their medication list at numerous appointments.

- 'My Medication Passport' (MMP), developed by the National Institute for Health Research Collaboration for Leadership in Applied Health Research and Care North West London (NIHR CLAHRC NWL), in collaboration with the NIHR Imperial Patient Safety Translational Research Centre, allows a patient-held record of medicines that allows an 'at-a-glance' view of the medication list for any treating clinician.

- Patient involvement was central to the development of MMP, which was originally intended for use in elderly patients.

- This pilot in a disabled child demonstrates the applicability of the principles of MMP to younger patients with complex medication needs, including medication administration challenges that are often left to parents and carers to solve.

- We recommend adapting the original MMP to provide a tool for use by the paediatric community to manage medicines more effectively. 
1. Routine review of MMP initiation and use by a paediatric pharmacist;

2. Space for parents/carers to explain how they administer medicines;

3. Space to state flavours that the child does not like;

4. Prompts to ask for advice from, for example, the pharmacist about administration.

CLAHRC for NWL are actively seeking input from the paediatric community in developing MMP for children and young people. We would like to hear from anyone who is interested in this work.

Acknowledgements With thanks to Elaine Smith, Vanessa Marvin and Shirley Kuo, pharmacists at the Chelsea \& Westminster Hospital London, for their helpful comments.

Contributors BJ and MB have each made substantial contributions to the design of this work; contributed to drafting the work; finally approved the version to be published; agreed to be accountable for all aspects of the work in ensuring that questions related to the accuracy or integrity of any part of the work are appropriately investigated and resolved.

Competing interests BJ is the father of the patient of this case study.

\section{Patient consent Obtained.}

Provenance and peer review Not commissioned; externally peer reviewed.

Disclaimer This article presents independent research commissioned by the National Institute for Health Research (NIHR) under the Collaborations for Leadership in Applied Health Research and Care (CLAHRC) programme for North West London.

The views expressed in this publication are those of the author(s) and not necessarily those of the NHS, the NIHR or the Department of Health.

\section{REFERENCES}

1 Health Service Journal (16.8.12) Passport to improved patient experience. http:// www.hsj.co.uk/resource-centre/best-practice/patient-involvement-resources/ passport-to-improved-patient-experience/5047524.article (accessed 30 Sep 2014).

2 Thakkar K. A project that puts medicines optimisation into patients' pockets. Clin Pharm 2014;6:135.

3 Medicines Standard: National Service Framework for Children, Young People \& Maternity Services. Medicines for children and young people. Department of Health 2004. https://www.gov.uk/government/uploads/system/uploads/attachment_data/file/ 199958/National_Service_Framework_for_Children_Young_People_and_Maternity_ Services-Medicines for_Children and Young People.pdf (accessed 30 Sep 2014).

4 Barber S, Thakkar K, Marvin V, et al. Evaluation of My Medication Passport: a patient-completed aide-memoire designed by patients, for patients, to help towards medicines optimisation. BMJ Open 2014;4:e005608.

Copyright 2015 BMJ Publishing Group. All rights reserved. For permission to reuse any of this content visit http://group.bmj.com/group/rights-licensing/permissions.

BMJ Case Report Fellows may re-use this article for personal use and teaching without any further permission.

Become a Fellow of BMJ Case Reports today and you can:

- Submit as many cases as you like

- Enjoy fast sympathetic peer review and rapid publication of accepted articles

- Access all the published articles

- Re-use any of the published material for personal use and teaching without further permission

For information on Institutional Fellowships contact consortiasales@bmjgroup.com

Visit casereports.bmj.com for more articles like this and to become a Fellow 